\title{
INVESTIGATION ON VOLUME VARIATION FOR ALPHA STIRLING ENGINES ON ISOTHERMAL MODEL
}

\author{
M. K. Gussoli ${ }^{a}$, \\ J. C. D. de Oliveira ${ }^{a, b}$ \\ M. Higa ${ }^{a, b}$ \\ ${ }^{a}$ Universidade Estadual de Maringá \\ Departamento de Engenharia Mecânica \\ Bairro Zona 7 \\ CP 87020-900, Maringá, Paraná, Brasil \\ mauriciogussoli@gmail.coma \\ jcdoliveira@uem.br ${ }^{\mathrm{b}}$ \\ mhiga@uem.br \\ Received: Dec 04, 2020 \\ Revised: Dec 15, 2020 \\ Accepted: Dec 16, 2020 \\ $\mathrm{L}_{\mathrm{i}} \quad$ connecting rod length, $\mathrm{m}$ \\ $\mathrm{n}$ rotational speed, $\mathrm{rpm}$ \\ $\mathrm{p}$ instantenous pressure, $\mathrm{kPa}$ \\ $\mathrm{p}_{\mathrm{m}} \quad$ mean operating pressure, $\mathrm{kPa}$ \\ $\mathrm{R}_{\text {gas }}$ gas constant, $\mathrm{J} /(\mathrm{kgK})$
}

\begin{abstract}
The usage of renewable energies is approximately $11 \%$ of the matrix energy worldwide. In countries known for its renewable sources, such as Brazil, the percentage is close to $38 \%$. The importance to study Stirling engines and propose a prototype is that they are a feasible alternative for generation of power and electricity when considering low quality sources such as solar and waste energy. This paper will compare two different approaches of the volume variation, sinusoidal and kinematic, using an isothermal model that represents the Stirling engines. The comparison is made for an $\alpha$ type engine. Such approaches are capable of representing an estimative of work and power output for Stirling engines since the difference of results for these approaches are $8.07 \%$ for power output. As both approaches are a valid choice for analyzing the Stirling engine cycle, the availability of the data determines which approach is the most suitable for characterizing the engine performance.
\end{abstract}

Keywords: Stirling engine; volume variation; alpha; isothermal model; working fluid mass

\section{NOMENCLATURE}

$\mathrm{A}_{\mathrm{i}} \quad$ area, $\mathrm{m}^{2}$

m mass, $\mathrm{kg}$

$\mathrm{P}_{\text {net }}$ power output, $\mathrm{W}$

$\mathrm{r}_{\mathrm{i}} \quad$ radius, $\mathrm{m}$

$\mathrm{T}_{\mathrm{i}} \quad$ temperature, $\mathrm{K}$

$\mathrm{V}_{\mathrm{i}} \quad$ volume, $\mathrm{m}^{3}$

$\mathrm{W}_{\mathrm{i}} \quad$ work, $\mathrm{J}$

$\mathrm{X}_{\mathrm{i}} \quad$ displacement, $\mathrm{m}$

\section{Greek symbols}

$\alpha, \beta, \gamma$ engine configuration

$\alpha_{\mathrm{f}} \quad$ phase angle $\left[^{\circ}\right]$

$\theta, \Delta \theta$ crank angle $\left[{ }^{\circ}\right]$

\section{Subscripts}

c cold space

ckin cold space for kinematic volume variation

dc dead volume in cold space

dh dead volume in hot space

h hot space

hkin hot space for kinematic volume variation

net net quantity

$\mathrm{r}$ regenerator space

sc swept cold volume

sh swept hot volume $\mathrm{t} \quad$ total quantity

\section{INTRODUCTION}

The Stirling engine was patented in 1816 by Robert Stirling as an alternative to the steam machines proposed by the manufactures in the Industrial Revolution (Thombare and Verma, 2008), due to the catastrophic accidents in quarries and coal mines (Wagner, 2008).

The interest in the Stirling engine is very high due to its fuel flexibility as it is essential for the adaptation of the machine in several environments, for example biomass, solar, residual energies, gaseous products of processes and so on (Badea, 2015; Ahmadi et al., 2017).

Expanding to a global scenario, 860 million people do not have access to electricity, which is an alerting fact that brings together the interest of the public and academic community in studying and proposing feasible solutions that combine both green energy sources and efficient systems (IEA, 2019).

According to Roser and Ritchie (2020), in 2018 the non-renewable sources represented the total energy consumption of $89.11 \%$, composed by oil, coal, natural gas and nuclear sources. The renewable sources are the remained $10.89 \%$, such as hydropower $(6.84 \%)$, wind $(2.07 \%)$, solar $(0.95 \%)$ and other renewables $(1.02 \%)$.

In Brazil, on the other hand, the non-renewable represents $62.58 \%$ of the energy consumption total, leading to $37.42 \%$ of renewable sources. The hydropower $(29.48 \%)$ leads the composition, followed by wind $(3.69 \%)$, solar $(0.24 \%)$ and other 
renewables (4.02\%). Also, according to EPE (Empresa de Pesquisa Energética), which is a public company subordinated to the MME (Ministério de Minas e Energia) in Brazil, the renewable energies participation in the matrix energy represented $45.3 \%$ in 2018. The energies included are the solar, wind, hydrological, the biomass and others sources (EPE, 2018). These data support Brazil's renewable sources in comparison to the world's matrix and sustains the interest in such sources.

The Stirling engines is also known as an alternative regenerative external combustion machine. This means that it works with its pistons alternatively within the thermodynamic cycle with regenerative processes. The regenerative processes are done by a metallic matrix which is a heat exchanger. The external combustion can be achieved by any kind of hot source, such as natural gas or liquefied petrol gas combustion, solar heating or residual energy (Wang et al., 2016).

The thermodynamic Stirling cycle is pictured in Fig. 1 by the pressure $x$ volume $(\mathrm{pV})$ diagram. The compression and expansion processes are shown thin and thick in dashed lines, respectively. The regenerative steps are shown in thick straight lines. The compression and expansion processes are considered isothermal for the ideal thermodynamic cycle, as well as the regenerative processes are considered isochoric (Thombare and Verma, 2008).

As a result of such arrangement, the ideal Stirling engine cycle outputs the same thermal efficiency as the Carnot cycle (Kim et al., 2017). However, the real Stirling cycle do not output the same work and thermal efficiency as the ideal cycle, since real machines have thermal and mechanical losses. Furthermore, the volume variation design of these machines may influence the power and efficiency output, as a result of the kinematic mechanism cannot follow the ideal volume variation likewise the $\mathrm{pV}$ diagram proposes (Costea et al., 1999; Li et al., 2016).

The Stirling engines are generally classified into gas coupling (free piston), fluid coupling and rigid coupling. The rigid coupling machines are the most common and some examples are the classic bell crank, crank rod, rhombic mechanism, and so on (Dincer, 2018; Egas and Clucas, 2018).

Moreover, the classification of the Stirling engines are usually supported by the arrangement of the pistons, displacers and chambers. The three configurations available are the $\alpha, \beta$ and $\gamma$. The first configuration consists of the two chambers being connected in series and uses two pistons. The second configuration has a piston and a displacer in the same chamber.

The latter is a variation of the beta configuration and possess two separated chambers, a piston and a displacer in each chamber (Dincer, 2018).

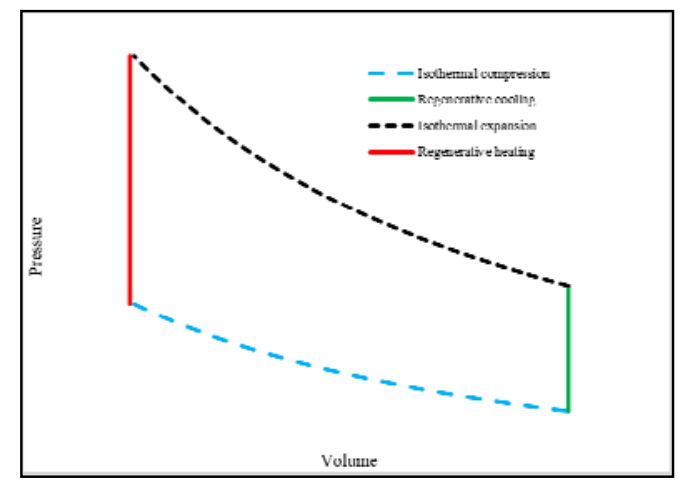

Figure 1. Ideal thermodynamic cycle for Stirling engines. Source: Authors (2020).

The Fig. 2- not in scale - shows a schematic drawing for the three configurations available for the Stirling machines.

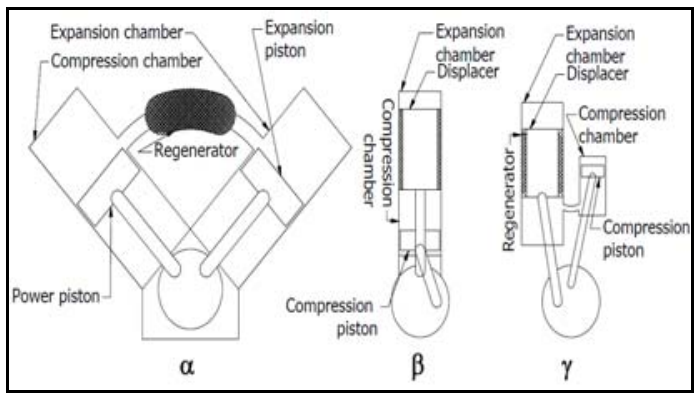

Figure 2. Available configurations for Stirling engines. Source: Authors (2020).

The regenerator can be used in all three configurations. This part is responsible for the increasing in the machine efficiency and cycle, since it is a heating buffer part that acts like a thermal sponge. In the compression stage, the regenerator releases heat to the working fluid. In the expansion stage, the regenerator captures the heat from the working fluid to its metallic matrix (Hachem et al., 2018). This part can be used as a stationary part or a moving element, in the case of $\beta$ and $\gamma$ configurations. The stationary configuration is more usual. If utilized as a moving part, it can be implemented within the displacer as one part.

There were several attempts of modeling the Stirling cycle, such as the isothermal model proposed by Schmidt in 1871, that was recognized as a closed solution for isothermal processes for compression and expansion (Walker, 1980). Nevertheless, the cycle remained highly idealized, since the thermal and mechanical losses were not incorporated in the modeling (Mueller-Roemer and Caines, 2015; Snyman et al., 2017; Ding et al., 2018).

Despite of the processes not being isothermal in the real cycle, the isothermal model - also referred in the literature as the Schmidt model - can be used to predict performance and discuss the Stirling engine. 
The modeling discussion in the Stirling engine subject is a long thread in history. There are several papers that emphasize different approaches in modeling the behavior of such machine (Egas and Clucas, 2018; Mueller-Roemer and Caines, 2015; Paul and Engeda, 2015; Ranieri et al., 2018). Nonetheless the goal was never to compare different machines to each other, in respect to their size or efficiency. The modeling objectives is the optimization of losses, efficiency or other variable of interest.

The operation in a Stirling engine starts with a volume variation. In a previous step, the volume variation of the machine is crucial to the application. In this paper, an $\alpha$ type Stirling engine is analyzed by two volume variation approaches: a sinusoidal and a kinematic (as also called as real piston displacement) set of equations.

The current state of art is focused in the sinusoidal modeling, since it is the simplest model available. Also, this approach results in a closed solution, proposed by Schmidt. On the other hand, the kinematic approach did not have the same attention by the academic community. Hence, the comparison of both approaches in order to analyze its particularities.

\section{MATERIALS AND METHODS}

For the isothermal model utilized in this paper, the mathematical modeling proposed by Ranieri et al. (2018) is the isothermal processes, which are being implemented in this paper. The hypotheses for this model are: 1) isothermal compression and expansion processes; 2) the gas behavior is described by the perfect gas law; 3) gas is atmospheric air; 4) the regeneration processes are ideal; 5) there are no leakages in the machine.

These hypotheses are valid for both volume variation approaches, since Ranieri et al. computes the sinusoidal model and this paper proposes the comparison of the sinusoidal and the kinematic volume variations.

\section{Sinusoidal Volume Variation}

In the case of sinusoidal approach, the expansion $\left(\mathrm{V}_{\mathrm{h}}\right)$ and compression $\left(\mathrm{V}_{\mathrm{c}}\right)$ are described by Eq. (1) and Eq. (2). The subscript " $h$ " and "c" stands for the expansion and compression spaces, respectively. The $\mathrm{V}_{\mathrm{sh}}$ is the volume swept by the displacer [m3], the $\mathrm{V}_{\mathrm{sc}}$ is the volume swept by the compression piston $\left[\mathrm{m}^{3}\right]$, the $\mathrm{V}_{\mathrm{dh}}$ and $\mathrm{V}_{\mathrm{dc}}$ are the dead volume $\left[\mathrm{m}^{3}\right]$, the $\theta$ is the crank angle $\left[{ }^{\circ}\right]$ and the $\alpha_{\mathrm{f}}$ is the phase angle of the machine $\left[^{\circ}\right]$ (Ranieri et al., 2018).

$$
\mathrm{V}_{\mathrm{h}}=\frac{\mathrm{V}_{\mathrm{sh}}}{2}(1-\cos (\theta))+\mathrm{V}_{\mathrm{dh}}
$$

$$
\mathrm{V}_{\mathrm{c}}=\frac{\mathrm{V}_{\mathrm{sc}}}{2}(1-\cos (\theta-\alpha))+\mathrm{V}_{\mathrm{dc}}
$$

\section{Kinematic Volume Variation}

The kinematic approach, for the $\alpha$ Stirling engine, is based on the motion equation for a single piston for both compression and expansion pistons. The compression piston has an $\alpha$ phase. The equation for the motion of a single piston is given by Bosch (2015).

Equations (3) and (4) describe the piston displacement for expansion $\left(\mathrm{X}_{\mathrm{h}}\right)$ and compression $\left(X_{c}\right)$, respectively. The $r_{h}$ and $r_{c}$ are the crank radius $[\mathrm{m}]$ and $\mathrm{L}_{\mathrm{h}}$ and $\mathrm{L}_{\mathrm{c}}$ are the length of the connecting rods, in respect to the displacer and piston (Parlak et al., 2009).

$$
\begin{aligned}
& X_{h}=r_{h}\left(1+\frac{r_{h}}{L_{h}}-\cos (\theta)-\sqrt{\frac{r_{h}}{L_{h}}-\sin (\theta)^{2}}\right) \\
& \left.X_{c}=r_{c}\left(1-\cos \theta-\alpha_{f}\right)+\frac{L_{c}}{r_{c}}\left(1-\sqrt{1-\left(\frac{r_{c}}{L_{c}}\right)^{2} \sin \left(\theta-\alpha_{f}\right)^{2}}\right)\right)
\end{aligned}
$$

The volume is calculated by multiplying the piston displacement by its area according to Eq. (5) and (6), where $A_{h}$ and $A_{c}$ are the areas of the expansion and compression pistons. Therefore, the volume for expansion and compression are $\mathrm{V}_{\mathrm{hkin}}$ and $\mathrm{V}_{\text {ckin }}$, respectively.

$$
\begin{gathered}
V_{\text {hkin }}=X_{h} A_{h}+V_{d h} \\
V_{\text {ckin }}=X_{c} A_{c}+V_{d c}
\end{gathered}
$$

\section{Isothermal Model}

Furthermore, the isothermal model stands by the ideal gas law. Ranieri et al. (2018) stated the mass of the system is calculated in the initial conditions of their experiment - Eq. (7) - and the pressure is given by Eq. (8).

To secure the model is indeed isothermal and the same proposed by Ranieri et al. (2018), the temperatures $T_{c}$ and $T_{h}$ are considered constants throughout the Stirling cycle. Therefore, the pressure is a function of the crank angle $\theta$ and the volumes of compression and expansion, for the respective model of volume variation.

$$
\begin{aligned}
\mathrm{m} & =\frac{\mathrm{p}_{\mathrm{m}} \mathrm{V}_{\text {sh }}}{\mathrm{R}_{\text {gas }} \mathrm{T}_{\text {room }}} \\
\mathrm{p}(\theta) & =\frac{\mathrm{mR}_{\text {gas }}}{\frac{\mathrm{V}_{\mathrm{h}}(\theta)}{\mathrm{T}_{\mathrm{h}}}+\frac{\mathrm{V}_{\mathrm{r}}}{\mathrm{T}_{\mathrm{r}}}+\frac{\mathrm{V}_{\mathrm{c}}(\theta)}{T_{\mathrm{c}}}}
\end{aligned}
$$


The mass of the system is denoted by $\mathrm{m}[\mathrm{kg}]$, $\mathrm{R}_{\text {gas }}$ is the gas constant $(287 \mathrm{~J} /(\mathrm{kg} . \mathrm{K})), \mathrm{p}_{\mathrm{m}}$ is the mean operation pressure $[\mathrm{Pa}], \mathrm{T}_{\text {room }}$ is the ambient temperature and equals to $298 \mathrm{~K}$.

For the regenerator, $V_{r}$ is the given volume of the regenerator $\left[\mathrm{m}^{3}\right]$ and $T_{\mathrm{r}}$ is the temperature of the regenerator $[\mathrm{K}]$. The latter is calculated by Eq. (9).

$$
\mathrm{T}_{\mathrm{r}}=\frac{\mathrm{T}_{\mathrm{h}}-\mathrm{T}_{\mathrm{c}}}{\ln \left(\mathrm{T}_{\mathrm{h}} / \mathrm{T}_{\mathrm{c}}\right)}
$$

Therefore, the total volume of the machine at a crank angle is defined by $\mathrm{V}_{\mathrm{t}}\left[\mathrm{m}^{3}\right]$, represented by Eq. (10). The total volume, for both sinusoidal and kinematic approaches, compute the variation within the crank angle and the dead volumes of the expansion and the compression spaces, in addition to the regenerator volume. The latter is considered a dead space, since it does not contribute to useful work within the cycle.

$$
\mathrm{V}_{\mathrm{t}}(\theta)=\mathrm{V}_{\mathrm{h}}(\theta)+\mathrm{V}_{\mathrm{r}}+\mathrm{V}_{\mathrm{c}}(\theta)
$$

The compression and expansion works are given by Eq. (11) and (12). The network is the sum of $\mathrm{W}_{\mathrm{c}}[\mathrm{J}]$ and $\mathrm{W}_{\mathrm{h}}[\mathrm{J}]$. The $\Delta \theta$ is an incremental angular displacement $\left[{ }^{\circ}\right]$ for calculations, which is given by the number of divisions for one revolution of the crank. The crank angle is separated in 360 divisions. For a given angular rotation, the power output $\left(\mathrm{P}_{\text {net }}\right.$ [W]) is the multiplication of the sum of compression and expansion work by the rotation $\mathrm{n}$ [rpm], given by Eq. (14):

$$
\begin{gathered}
\mathrm{W}_{\mathrm{c}}(\theta)=\mathrm{p}(\theta)\left(\mathrm{V}_{\mathrm{c}}(\theta+\Delta \theta)-\mathrm{V}_{\mathrm{c}}(\theta)\right) \\
\mathrm{W}_{\mathrm{h}}(\theta)=\mathrm{p}(\theta)\left(\mathrm{V}_{\mathrm{h}}(\theta+\Delta \theta)-\mathrm{V}_{\mathrm{h}}(\theta)\right) \\
\mathrm{W}_{\text {net }}(\theta)=\mathrm{W}_{\mathrm{c}}(\theta)+\mathrm{W}_{\mathrm{h}}(\theta) \\
\mathrm{P}_{\text {net }}=\frac{\mathrm{W}_{\text {net }} \mathrm{n}}{60}
\end{gathered}
$$

The model is implemented in Scilab, which is a free and open source software for engineering applications.

To validate the modeling of the isothermal model proposed by Ranieri et al. enhanced by the kinematic approach, the geometric data utilized is retrieved from Garcia et al. (2018), since the geometrical lengths and dimensions of the $\alpha$ Stirling engine are available. Such data is limited in the literature, because the volume variation modeling is focused on the sinusoidal approach.
The $\alpha$ Stirling engine is called GENOA03, which is a prototype studied by Garcia et al. The data retrieved is shown in Tab. 1 .

Table 1. Data retrieved from Garcia et al. (2018)

\begin{tabular}{cc}
\hline & Operational parameters \\
\hline$T_{c}$ & $293[\mathrm{~K}]$ \\
$T_{h}$ & $1023[\mathrm{~K}]$ \\
$p_{m}$ & $1500[\mathrm{kPa}]$ \\
$n$ & $600[\mathrm{rpm}]$ \\
\hline \multicolumn{2}{c}{ Geometrical } \\
\hline $\mathrm{d}$ & $110 \mathrm{e}-3[\mathrm{~m}]$ \\
$\mathrm{L}$ & $30 \mathrm{e}-3[\mathrm{~m}]$ \\
& $210 \mathrm{e}-3[\mathrm{~m}]$ \\
\hline $\mathrm{V}_{\mathrm{sh}}, \mathrm{V}_{\mathrm{sc}}$ & $524.6 \mathrm{e}-6\left[\mathrm{~m}^{3}\right]$ \\
$\mathrm{V}_{\mathrm{dh}}, \mathrm{V}_{\mathrm{dc}}$ & $153.3 \mathrm{e}-6\left[\mathrm{~m}^{3}\right]$ \\
$\mathrm{V}_{\mathrm{r}}$ & $472.62 \mathrm{e}-6\left[\mathrm{~m}^{3}\right]$ \\
\hline
\end{tabular}

The parameter $\mathrm{d}$ stands for the diameter $[\mathrm{m}], \mathrm{r}$ for the crank radius [m], $\mathrm{L}$ is the length of the connecting rod $[\mathrm{m}]$ and $\mathrm{n}$ is the output rotational speed [rpm]. These parameters describe both the piston and displacer of the machine. This engine is an $\alpha$ type Stirling engine with pressurized operation.

\section{RESULTS AND DISCUSSION}

The ideal Stirling cycle is useful to predict its performance and redesign parts for the engine. Figure 3 shows the ideal Stirling cycle (thick solid line) and the isothermal model (dotted line) proposed by Schmidt for the GENOA03 Stirling engine. Even though both ideal and isothermal models are supported by constant temperatures in the compression and expansion processes, the ideal model does not account volume variation. The ideal model just computes the state of the working fluid by the ideal gas law, whilst the isothermal model accounts the volume variation as the crank angle changes.

At a first glance, the pressures and net work by the ideal Stirling cycle is much higher than the proposed by the isothermal model. The useful work done by the ideal and the sinusoidal cycle are $6.341 \mathrm{~kJ}$ and $0.716 \mathrm{~kJ}$, respectively. The pressure ratio in respect to each cycle is 6.26 and 2.09. Such difference remains in the initial mass calculation. Ranieri's isothermal model calculated the mass of the system by Eq. (7). This initial condition for a high pressure operation of $1500 \mathrm{kPa}$ forces the mass to be higher than in reality. The calculated mass is $0.0303 \mathrm{~kg}$, which is 20 times higher than the calculated by Garcia et al. (2018). This big difference in results for mass lies in the fixed calculation of the mass of the system by Ranieri et al. (2018) and the interactive corrections of the mass for the Garcia's model. This is the reason it is expected to have high values for working with this model. 
Yet, the isothermal model represents a better perspective for the performance of the machines. This model points the behavior of the working fluid at its properties at the beginning and at the end of the thermodynamic cycle, in other words, the pressure of the working fluid at the bottom and top dead center of the piston and displacer. This is expressed by the rounded shape of the $\mathrm{pV}$ slope for the isothermal model, compared to the ideal cycle.

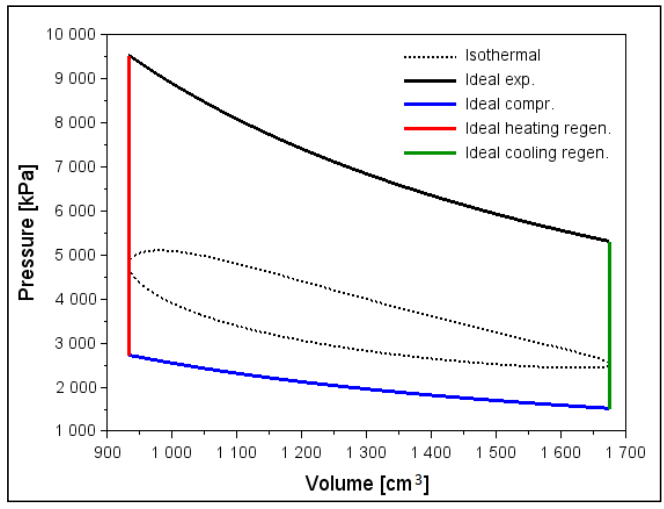

Figure 3. Ideal Stirling cycle and isothermal Stirling cycle.

The regenerative processes are not completely isochoric in the isothermal modeling. At a portion of the piston and displacer displacement the expansion and the compression processes are isochoric. These behaviors are considered losses within the arrangement of the system as a whole. Therefore, the optimization of the machine could return higher net work.

The Fig. 4 returns a volume variation for both sinusoidal and kinematic approaches. Both approaches for volume variation for an $\alpha$ type Stirling engine presented the same behavior. But there are some differences in absolute values for each crank angle. The sinusoidal approach lies in Eq. (1) and Eq. (2), calculating the volume only by the swept volume of the piston and the crank angle.

The kinematic approach, on the other hand, relies on the geometry of the mechanism - Eq. (5) and Eq. (6). If the mechanism chosen stands for bigger geometrical parameters, such as lengths and radius, the volume variation can be higher. Also, the description of the displacement of a piston, given by Eq. (3) and Eq. (4), lies on the squared and square root of the geometrical parameters. These mathematical issues introduce non-linearity to the volume variation.

For the expansion volume, as the cycle begins and at the ending, both approaches give the same volume. Within the cycle development, the kinematic volume variation is higher than the sinusoidal. The relative difference between the maximum volume for both approaches are $6.30 \%$, which represents the maximum relative deviation.

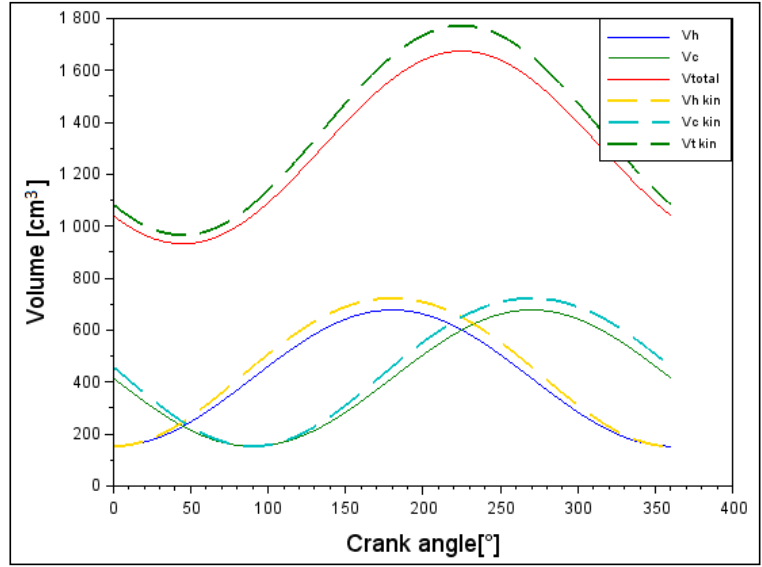

Figure 4. Volume variation for sinusoidal and kinematic approaches.

The minimum values for the expansion values are the same, since this configuration occurs at the zero degree angle. For this angle, the cosine is equal to one and the sine is zero, leading the Eq. (1) and Eq. (5) to the value of the dead volume of the expansion space. The compression behavior is the opposite, but as the crank angle develops its rotational displacement towards $90^{\circ}$, the volumes for the compression in both approaches are the same. The maximum deviation for the compression volume is $6.72 \%$, which occurs at the $270^{\circ}$ angle. For this angle, Eq. (2) and Eq. (6) corresponds to the values of the swept volume for compression and its dead volume, for both approaches. This leads to the same value for the volume at $270^{\circ}$.

For the total volume, it is computed the dead volume of the regenerator, as shown in Eq. (10). The dead volumes of the compression and expansion spaces are already computed in the set of equations for volume variation, as shown by Eq. (1), Eq. (2), Eq. (5) and Eq. (6). Therefore, the total volume has higher volumes than the summation of compression and expansion volumes due to the volume of the regenerator of the machine, as shown in Fig. 4.

The pressure variation for both models have the same behavior. As well as the volume variation, there are some variations near the $90^{\circ}$ and the $180^{\circ}$ to $270^{\circ}$, which are the most visible in the slopes shown. The kinematic slope has lower values for pressure Figure 5 (thick solid line) - since the volume, in respect for each crank angle, is higher for the kinematic (dashed line), also shown in Fig.5. This behavior is expected, since the ideal gas law is utilized in the model.

The higher absolute difference in pressure between approaches is $213.6 \mathrm{kPa}$ in the zero degree angle. The higher volume absolute difference in volume is $9.83 \times 10^{-5} \mathrm{~m}^{3}$, which occurs around $230^{\circ}$. This differences of pressure are expected to be high, since the mass calculation interferes in the pressure calculation. The volume differences are a consequence of the mechanism geometry. 


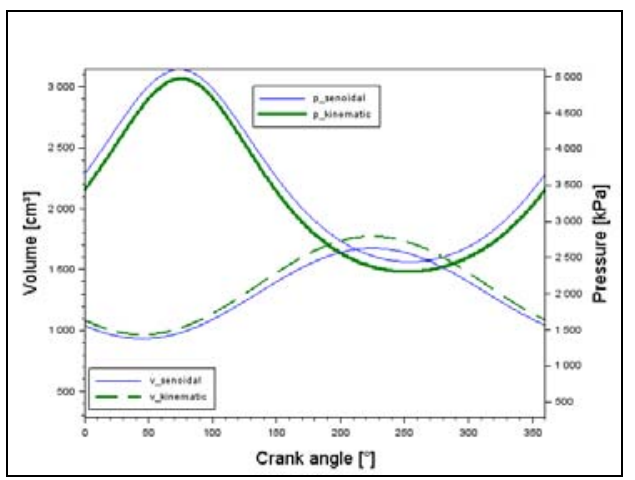

Figure 5. Pressure and volume variation for sinusoidal and kinematic approaches.

The isothermal $\mathrm{pV}$ diagram for the GENOA03 Stirling engine is depicted in Fig. 6. The kinematic approach (solid line) returns a larger $\mathrm{pV}$ diagram than the sinusoidal approach (dashed line). The work is 716.54J and 779.49J, for the sinusoidal and kinematic approaches respectively. The power output is rated at $7.16 \mathrm{~kW}$ and $7.79 \mathrm{~kW}$, at $600 \mathrm{rpm}$, with a relative difference of $8.07 \%$. This relative difference sustains that both models are capable of describing the isothermal Stirling cycle.

Nonetheless the Ranieri et al. (2018) modelling do not update the mass of the engine like the implementation made by Garcia et al. (2018). That is the reason for the pressure depicted in Fig. 5 (thin solid line) which is higher than the original paper, it is not reliable for pressurized engines. For the model implemented in this paper, the mass of air in the engine was calculated as $0.033 \mathrm{~kg}$ for both approaches, respecting the model proposed by Ranieri et al. (2018) whose configuration of the mass of the system is given by Eq. (7).

For the same data, Garcia et al. (2018) calculated $0.00144 \mathrm{~kg}$ of working fluid in the pressurized engine. Garcia et al. (2018) have the working fluid mass as the convergence criteria. Ranieri et al. (2018) do not update the working fluid mass. Therefore, overestimating the mass value.

Such model described by Ranieri et al. (2018) does not demand geometrical parameters like crank and connecting rods lengths, which is an advantage to smooth and ease the computational implementation and analysis. On the other hand, kinematic analysis can describe the precision of the displacement as it happens within the thermodynamic cycle. This can be useful in some innovative mechanisms and Stirling engine design.

In conclusion, the kinematic approach is useful if there is available data from a new design or measurements from an existing machine. Conversely, if only the swept volumes are known, then a characterization of the machine is possible by the sinusoidal approach.

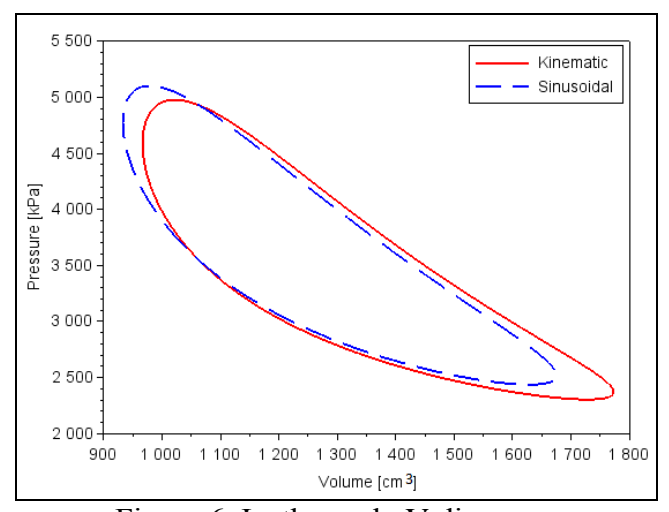

Figure 6. Isothermal pV diagram.

\section{CONCLUSIONS}

This paper investigated two different approaches for volume variation in Stirling engines. For an isothermal model, the little difference between both volume variation approaches did not impact the output result as much as the working fluid mass calculation. It was discovered and discussed about the influence of mass calculation for isothermal models. Nonetheless, both sinusoidal and kinematic approaches are valid methodologies to analyze $\alpha$ Stirling engines. The future work in this matter consists in proposing a mass update routine and compare its results to the literature.

\section{REFERENCES}

Ahmadi, M.H., Ahmadi, M.-A., Pourfayaz, F., 2017, Thermal models for analysis of performance of Stirling engine: A review. Renewable and Sustainable Energy Reviews, Vol. 68, pp. 168-184.

Badea, N., 2015. Design for Micro-Combined Cooling, Heating and Power Systems, Green Energy and Technology. Springer London, London.

$\mathrm{BOSCH}, 2015$. Manual de Tecnologia Automotiva. Blucher, Germany, 25th edition.

Costea, M., Petrescu, S., Harman, C., 1999, The effect of irreversibilities on solar Stirling engine cycle performance. Energy Conversion \& Management, Vol. 40, pp. 1723-1731.

Dincer, I., 2018. Comprehensive energy systems. Ibrahim Dincer, Canada.

Ding, G., Chen, W., Zheng, T., Li, Y., Ji, Y., 2018, Volume ratio optimization of Stirling engine by using an enhanced model. Applied Thermal Engineering, Vol. 140, pp. 615-621.

Egas, J. and Clucas, D., 2018, Stirling Engine Configuration Selection. Energies, Vol. 11, pp. 584.

EPE, 2018. "Balanço Energético Nacional 2019 (Relatório síntese)”. Empresa de Pesquisa Energética, Rio de Janeiro, Brazil.

García, M.T., Trujillo, E.C., Godiño, J.V., Martínez, D.S., 2018, Thermodynamic Model for Performance Analysis of a Stirling Engine Prototype. Energies, Vol. 11, pp. 2655. 
Hachem, H., Gheith, R., Aloui, F., Ben Nasrallah, S., 2018, Technological challenges and optimization efforts of the Stirling machine: A review. Energy Conversion and Management, Vol. 171, pp. 1365-1387.

IEA, 2019, SDG7: Data and Projections (Report). International Energy Agency, Paris, France.

Kim, Y., Chun, W., Chen, K., 2017, ThermalFlow Analysis of a Simple LTD (Low-TemperatureDifferential) Heat Engine. Energies, Vol. 10, pp. 567.

Li, R., Grosu, L., Queiros-Condé, D., 2016, Losses effect on the performance of a Gamma type Stirling engine. Energy Conversion and Management 114, 28-37.

Mueller-Roemer, C. and Caines, P.E., 2015, An Isothermal Energy Function State Space Model of a Stirling Engine. IFAC-Vol. 48, pp. 634-639.

Parlak, N., Wagner, A., Elsner, M., Soyhan, H.S., 2009, Thermodynamic analysis of a gamma type Stirling engine in non-ideal adiabatic conditions. Renewable Energy, Vol. 34, pp. 266-273.

Paul, C.J. and Engeda, A., 2015, Modeling a complete Stirling engine. Energy, Vol. 80, pp. 85-97.

Ranieri, S., Prado, G., MacDonald, B., 2018, Efficiency Reduction in Stirling Engines Resulting from Sinusoidal Motion. Energies, Vol. 11, pp. 2887.

Ritchie, H. and Roser, M., 2020, Energy - Our World in Data. 28 Apr. 2020 $<$ https://ourworldindata.org/energy $>$.

Snyman, H., Harms, T.M., Strauss, J.M., 2017, Design analysis methods for Stirling engines. J. energy South. Afr. Vol. 19, pp. 4-19.

Thombare, D. and Verma, S.K., 2008, Technological development in the Stirling cycle engines. Renewable and Sustainable Energy Reviews, Vol. 12, pp. 1-38.

Wagner, A., 2008. Calculations and experiments on gamma type Stirling engines. Doctoral Thesis, Cardiff University, Gales.

Walker, G., 1980. Stirling engines. Oxford University Press, England.

Wang, K., Sanders, S.R., Dubey, S., Choo, F.H., Duan, F., 2016, Stirling cycle engines for recovering low and moderate temperature heat: A review. Renewable and Sustainable Energy Reviews, Vol. 62, pp. 89-108. 